\title{
Composite Materials for Wear-Resistant Layers Made Using Electro-Spark Deposition
}

\author{
Joanna Kulasa (Institute of Non-Ferrous Metals, Sowińskiego 5 44-100 Gliwice, Poland) \\ Barbara Juszczyk (Institute of Non-Ferrous Metals, Sowińskiego 5 44- 100 Gliwice, Poland) \\ Marcin Lis (Institute of Non-Ferrous Metals, Sowińskiego 5 44-100 Gliwice, Poland) \\ Wojciech Burian (Institute of Non- Ferrous Metals, Sowińskiego 5 44-100 Gliwice, Poland) \\ Witold Malec (Institute of Non-Ferrous Metals, Sowińskiego 5 44-100 Gliwice, Poland) \\ Jaroslav Kováčik (Integrated Research of Materials and Their Applications IVMA STU s.r.o Bratislava, \\ Slovakia) \\ Štefan Emmer (Integrated Research of Materials and Their Applications IVMA STU s.r.o Bratislava,
} Slovakia)

\begin{abstract}
This paper presents the results of the investigation of composite sinters $\mathrm{W}-\mathrm{TiB}_{2}$ which were used as an electrode in the process of electro-spark deposition (ESD) and the examination of the deposited layers. The scope of the study includes detailed characteristics of powder mixtures, composite sinters made using the spark plasma sintering method (SPS) and layers deposited in the electro-spark process. The ESD process, using the $\mathrm{W}+30$ vol. $\% \mathrm{TiB}_{2}$ electrode, was carried out using an automated device. The substrates were made of copper and aluminium. The topography analysis of the surfaces of the composite layer and the evaluation of their wear resistance properties are also presented. The analysis of the results of research showed the possibility to obtain, using the SPS method, composite materials of good quality, which can be used as electrodes in the ESD process. The obtained layers had increased wear resistance in relation to the substrate material.
\end{abstract}

\section{Keywords}

Additive Manufacturing, 3D printing

\section{INTRODUCTION}

Electro-spark deposition allows to obtain hard and wear-resistant coatings on metallic substrates. The only essential condition is that both the substrate and electrode materials ought to be electrically conductive. A significant advantage is that due to the diffusion of electrode material into the substrate and vice versa, it is possible to obtain good bonding between the layer and the substrate. The deposited layer is often composed of the substrate material, and also new phases form due to chemical reactions taking place during deposition and rapid cooling. The advantage of this method is the ability to deposit material with a high melting point and to achieve good bonding to low temperature melting substrates, all at low thermal input. Due to the small heat affected zone, thermal stresses are small, and also there is minimal cracking in deposited layers. ESD is a pulsed micro-welding process that was developed originally for small scale and precision to repair high value components which were worn. The principal industrial applications of this method include repairing defects in casting moulds and injection moulding tooling. In general, all ESD systems contain a capacitor-based power supply that produces short high current pulses through a vibrating wire consumable electrode. The electrode material is deposited onto a work piece by means of electric sparks in a manner reverse to spark erosion (the electrode is the anode and the work piece is the cathode). When the capacitor energy is released, the direct current generates a plasma arc at a high temperature between the tip of the electrode and the work piece. The plasma arc ionises the electrode, and a small quantity of molten electrode material is transferred onto the work piece. The transfer of the material is rapid and self-quenching is extremely fast [1-6].

Based on short duration, high current pulses, the process imparts a low heat input to the substrate material, resulting in little or no modification of the substrate microstructure. Therefore, the process offers an advantage over fusion welding processes (including arc, laser, and resistance welding) when repairing materials that are difficult to weld because of poor heat affected zone properties (e.g. liquation cracking, high hardness, low toughness). Components can be restored to their original dimensions because with such low heat input the bulk substrate material remains near to ambient temperature with thermal distortion, shrinkage, and high residual stresses avoided. Moreover, the process generates a good metallurgical bond between the coating and the substrate [7].

Studies on the ESD of $\mathrm{Al}_{2} \mathrm{O}_{3}-\mathrm{TiB}_{2}$ and $\mathrm{ZrB}_{2}-\mathrm{TiB}_{2}$ composite coatings are discussed in works [7-9]. The authors also show that coating quality can be improved by depositing an $\mathrm{Al}_{2} \mathrm{O}_{3}-\mathrm{TiB}_{2}$ composite onto a Ni interlayer $[8,10]$.

The paper presents a part of the results of project APVV SK-PL-2015-0003 "Wear resistant and electrically conductive composite coatings on non-ferrous metals." The project was carried out in 
cooperation with the Department of Integrated Research of Materials and Their Applications, IVMA STU 
s.r.o in the framework of the programme for exchange of personnel participating in scientific and research projects between Poland and Slovakia in 2016-2017. It was proposed to use composite electrodes (e.g. in the form of $\mathrm{W}+30$ vol. $\% \mathrm{TiB}_{2}$ ) for electro-spark deposition of hard wear-resistant layers on metallic substrates.

The aim of the proposed work was to carry out detailed studies on powder mixture $\mathrm{W}+30$ vol. $\% \mathrm{TiB}_{2}$ and comprehensive evaluation of composite sinters produced in the SPS process, performing the role of electrodes in the electro-sparking process of depositing composite layers, and evaluation of the wear of the produced layers on substrates made of non-ferrous metals.

\section{MATERIALS AND METHODS}

The tested material was powder mixture $\mathrm{W}+30$ vol.\% $\mathrm{TiB}_{2}$ obtained from pure tungsten powder and $\mathrm{TiB}_{2}$ powder with the purity of $99.4 \%$ and the following composition: $>66 \% \mathrm{Ti},>29 \% \mathrm{~B},<2.0 \% \mathrm{C},<2.5 \%$ $\mathrm{B}_{2} \mathrm{O}_{3},<2.5 \% \mathrm{O},<0.8 \% \mathrm{~N}$ and $<0.3 \% \mathrm{Fe}$. The mixing process was carried out dry in a turbine mixer for 30 minutes.

The analysis of the morphology of the prepared powder mixture and microstructure investigation of the obtained composite sinters was carried out using scanning microscopy. For this purpose, the Zeiss Evo MA10 microscope was used, and in order to identify the chemical composition in micro-areas, energydispersive analysis (EDS) was used on a Bruker XFlash® 5010 EDS spectrometer. The density of the powder mixture was measured with an AccuPyc 1330 helium instrument, while its specific surface area was measured using a Micromeritics Gemini 2360 device. To determine the particle size distribution of the powder mix, a Fritsch NanoTec analyssette 22 device, that uses the physical principle of dissipating electromagnetic waves, was used. The analysis of phase composition of the powder mixture and composite sinters was carried out on the basis of the interpretation of diffraction patterns prepared with a Seifert-FPM XRD7 X-ray diffractometer.

The sintering process of composite powders was carried out using an FCT-HP D5/2 SPS device for spark plasma sintering. The density of composite sinters was measured using the Archimedes method. The composite sinters produced were electrodes in the electro-spark deposition process. The deposition process was carried out with the use of a device owned by IVMA STU Integrovaný výskum materiálov a ich aplikácií STU s.r.o. The device is computer controlled, which ensures repeatability of the deposition process.

The observation of the surface of deposited composite layers on non-ferrous metal substrates was carried out using an Olympus GX71 optical microscope and a scanning electron microscope.

The evaluation of tribological properties was carried out using wear tests performed at room temperature by means of a CSM Instruments THT Pin(Ball)-on-Disk high-temperature tribometer. The observation of the wear track on the samples was carried out using an Olympus GX71 metallographic microscope.

\section{RESULTS AND DISCUSSION}

The analysis of the morphology of mixture $\mathrm{W}+30$ vol. \% $\mathrm{TiB}_{2}$ (Fig. 1a) showed that the course of the mixing process was correct and a homogeneous powder mixture was obtained. The chemical composition of the mixture is consistent with the assumed one. The tungsten powder used in the mixture is characterised by granular shape with grain size $<6 \mu \mathrm{m}$, while the $\mathrm{TiB}_{2}$ powder is characterised by an irregular structure with an angular shape and grain size below $30 \mu \mathrm{m}$. The analysis of test results for mixture $\mathrm{W}+30$ vol.\% $\mathrm{TiB}_{2}$ showed that the mixture is characterised by a density of $13.35 \mathrm{~g} / \mathrm{cm}^{3}$ and a BET specific surface area of $0.24 \mathrm{~m}^{2} / \mathrm{g}$. The analysis of grain size distribution of the mixture showed that $90 \%$ of the mixture consists of grains with a particle diameter below $33.58 \mu \mathrm{m}, 10 \%$ of particles have a diameter smaller than $4.03 \mu \mathrm{m}$, and $50 \%$ of particles have a diameter smaller than $11.54 \mu \mathrm{m}$.

Composite sinters were made to obtain composite electrodes for the electro-spark deposition process for coatings made of powder mixture $\mathrm{W}+30$ vol.\% $\mathrm{TiB}_{2}$. The composites were obtained using the spark plasma sintering method (SPS). Due to the possibility of a reaction of the materials with the walls of the graphite matrix and for easier extraction of the sinters, graphite foil inserts were used. The following SPS parameters were used: sintering temperature of $1800^{\circ} \mathrm{C}$, pressing force of $22 \mathrm{kN}$, time of $300 \mathrm{~s}$, heating rate of $1.67^{\circ} \mathrm{C} / \mathrm{s}$, and initial air pressure at the start of the process less than $3 \mathrm{hPa}$. The obtained composite sinters $\mathrm{W}_{+} \mathrm{TiB}_{2}$ were characterised by a density of $14.13 \mathrm{~g} / \mathrm{cm}^{3}$, which is approx. $95.3 \%$ of theoretical density. The analysis of chemical composition and morphology of composite sinters, carried out in several areas for each sinter, showed that in each case homogeneous composites with the assumed chemical composition were obtained. In some analysed sinters (Fig. 1b), the occurrence of 
pores (voids) was observed, which probably could have occurred as a result of detachment of hard particles in the process of preparation of microsections (grinding).

a)

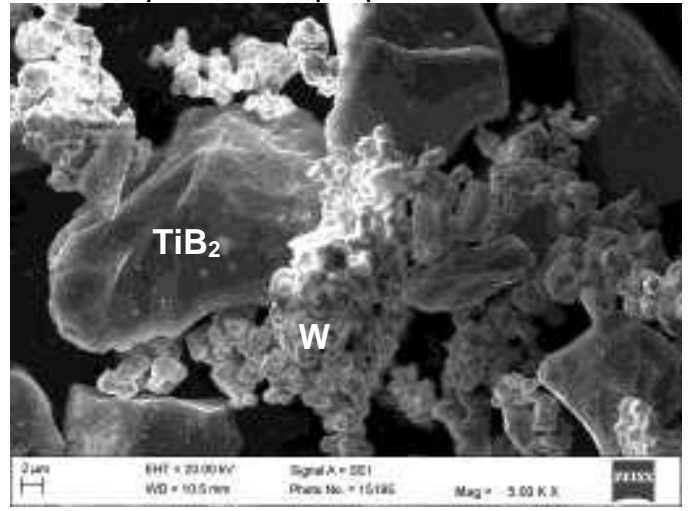

b)

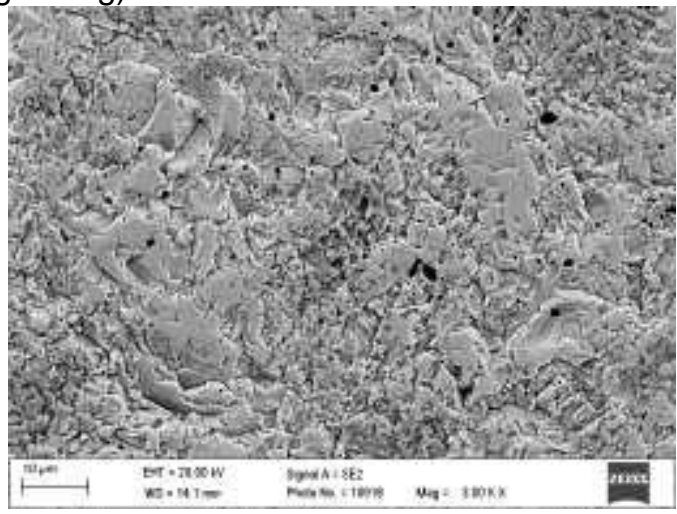

Fig. 1. SEM image of $\mathrm{W}+30$ vol. $\% \mathrm{TiB}_{2}$ : powder mixture (a), composite sinter (b)

The results of qualitative phase analysis (Fig. 2) of the analysed sinter $\mathrm{W}_{+} \mathrm{TiB}_{2}$ indicate a multi-phase structure of the material. Some of the spikes may be attributed to tungsten borides WB (with a tetragonal 141/amd and orthorhombic Cmcm structure) and $\mathrm{W}_{2} \mathrm{~B}$ (with a tetragonal $14 / \mathrm{mcm}$ structure). The presence of a fine-crystalline oxide $\mathrm{TiO}$ is also probable. In the diffraction pattern, there are also spikes with a very low intensity, which have not been clearly identified. A number of low-intensity diffraction spikes may correspond to various titanium oxides, including the non-stoichiometric Magnéli phases (e.g. $\mathrm{Ti}_{4} \mathrm{O}_{7}$ ). $\mathrm{The}$ presence of traces of graphite, probably the residue after the use of graphite inserts in the SPS process, is probable.

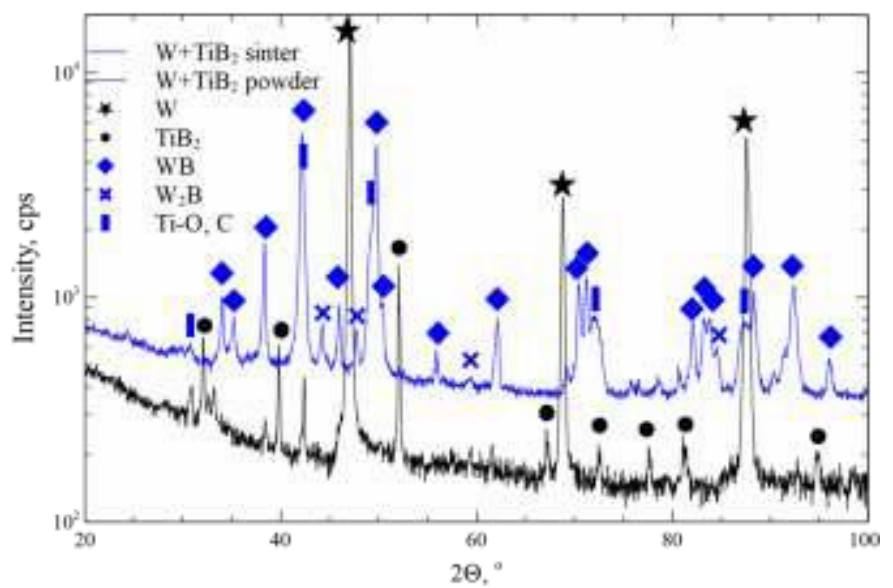

Fig. 2. X-ray diffraction pattern of $\mathrm{W}+30$ vol. $\% \mathrm{TiB}_{2}$ powder mixture and composite sinter

The obtained composite sinters were used as electrodes in the electro-spark deposition process The deposition process was carried out using an automated equipment for computer controlled ESD. Substrates were made of copper and AW7075 PM. The samples were mounted inside jaws, and using a CNC controlled SZ 08 device (Fig. 3a) the composite layers were electro-spark deposited under the following deposition parameters: working frequency $475 \mathrm{~Hz}$, voltage $25 \mathrm{~V}$, power performance from $25 \%$, direction of rotation of working electrode - right, rotational speed $10 \mathrm{rpm}$, and protective argon atmosphere was used during all experiments. The samples were subjected to 3 stages of deposition of the same parameters with SiC 600 polishing after each layer deposited. Both the traditional manual method of deposition (HD) as well as automatic deposition (AD) were used. An exemplary deposition process of composite layer $\mathrm{W}_{+} \mathrm{TiB}_{2}$ on substrate AW7075 PM is shown in Fig. $3 \mathrm{~b}$.

a)

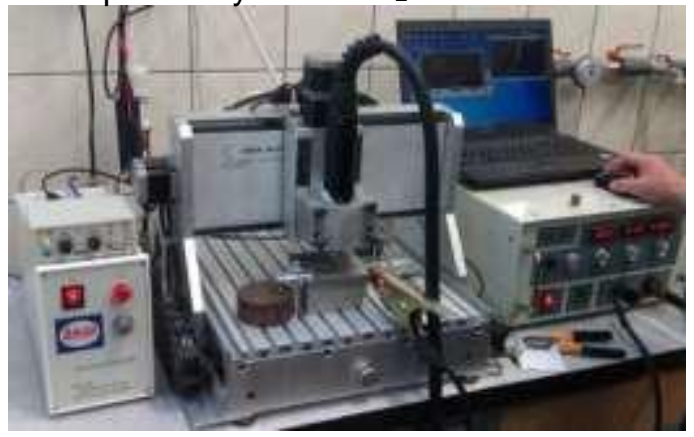

b)

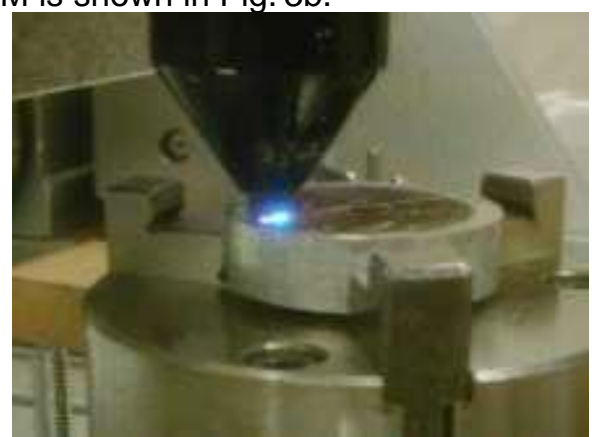


Fig. 3. Automated equipment for computer controlled ESD on a flat substrate (a), ESD process of the composite layer deposition on an aluminium alloy substrate using a $\mathrm{W}+\mathrm{TiB}_{2}$ electrode (b)

An example of a wear-resistant layer obtained on a copper substrate with the electro-spark deposition method (IVMA STU, Slovakia) with a $\mathrm{W}+\mathrm{TiB}_{2}$ composite electrode obtained using the spark plasma sintering method (IMN Poland) is shown in Fig. 4. The deposited layers are characterised by a good metallurgical bonding with the substrate. The analysis of topography of the composite layers showed that the deposited layers are characterised by surface roughness, which is characteristic for these types of layers, and in some cases by uneven deposition (covering) of the substrate.
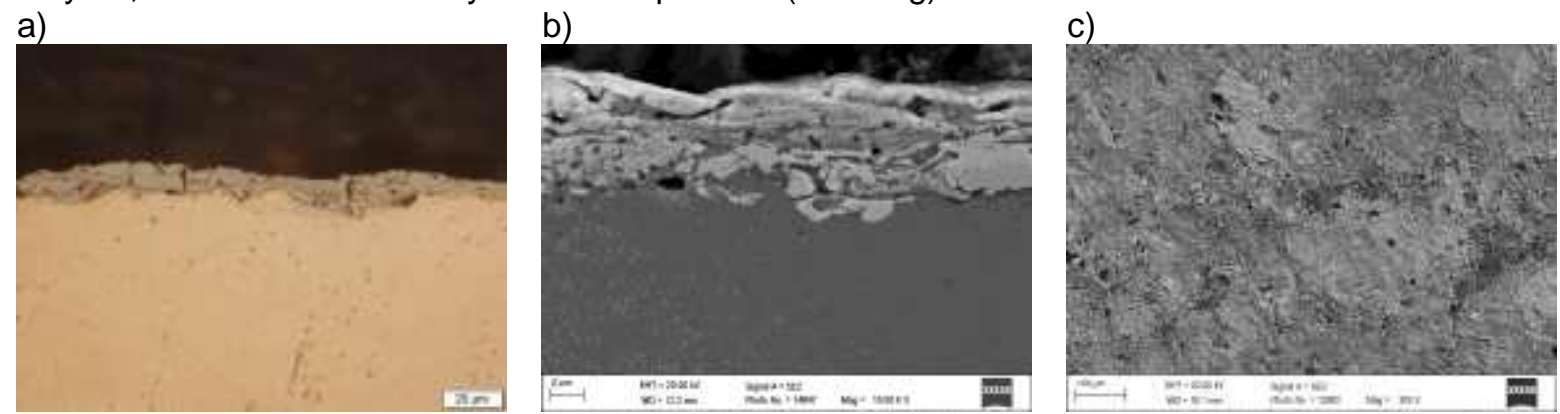

Fig. 4. $\mathrm{W}+\mathrm{TiB}_{2}$ composite layer on a copper substrate: cross-section $(\mathrm{a}, \mathrm{b})$, surface (c)

The assessment of tribological properties (friction coefficient, wear) of deposited composite layers was carried out using a high-temperature Pin-on-Disk tribometer. The tests were carried out under conditions of technically dry friction at ambient temperature and relative air humidity of $43 \pm 6 \%$. A counter-sample in the form of a ball with a diameter of $6 \mathrm{~mm}$ made of $\mathrm{Al}_{2} \mathrm{O}_{3}$ was used for the tests. Prior to the tests, the counter-sample was degreased in acetone. Then, both the sample and the counter-sample were weighed before and after the test, and the weight loss was determined based on the weight difference. A laboratory scale with a resolution of $0.0001 \mathrm{~g}$ was used to determine the weight. Wear tests were carried out for both the substrate materials (Cu, AW7075 PM) and samples with the deposited layer, i.e.: W+TiB $/ \mathrm{Cu}$ (AD), W+TiB $/ \mathrm{Cu}$ (HD), W+TiB $/$ AW7075 PM (AD) and W+TiB $2 / A W 7075$ PM (HD). Tribological tests were carried out at a constant load of $5 \mathrm{~N}$. The friction distance was $1000 \mathrm{~m}$, linear speed was $0.06 \mathrm{~m} / \mathrm{s}$, while the radius of the wear track was $8 \mathrm{~mm}$. A new sample and counter-sample was used for each test. The analysis of the results of tribological tests showed that the deposited layers on copper substrate are characterised by a higher average value of friction coefficient $(0.506 \pm 0.044$ for the automatically deposited layer and $0.482 \pm 0.055$ for the manually deposited layer) as compared to the copper substrate, for which the obtained average value of friction coefficient was $0.402 \pm 0.048$. The course of friction coefficient as a function of sliding distance for the tested materials is shown in Fig. 5 . The analysis of the friction coefficient as a function of sliding distance in the case of $\mathrm{W}_{+} \mathrm{TiB}_{2} / \mathrm{Cu}_{(\mathrm{AD})}$ showed that in the initial test run, the friction coefficient increases to approx. 0.500, and then, after crossing the distance of approx $150 \mathrm{~m}$, the course stabilises and maintains its average value of approx. 0.510 until the end of the test. The $\mathrm{W}+\mathrm{TiB}_{2} / \mathrm{Cu}(\mathrm{HD})$ sample is characterised by a similar stable course of changes in the friction coefficient. A different character of the curve was observed in the case of the tested copper substrate, where at the initial stage of the test, there is an increase in friction coefficient to the value of 0.381 , followed by fluctuations in friction coefficient, then, after crossing the distance of approx. $400 \mathrm{~m}$, the value of friction coefficient stabilises and until the end of the test, it shows an upward trend. Layers deposited on the AW7075 PM substrate are characterised by a similar stable course of the value of friction coefficient of $0.453 \pm 0.017$ for $W+\mathrm{TiB}_{2} / \mathrm{AW} 7075 \mathrm{PM}(\mathrm{AD})$ and $0.481 \pm 0.033$ for $\mathrm{W}+\mathrm{TiB}_{2} / \mathrm{AW} 7075 \mathrm{PM}(\mathrm{HD})$. The average value of friction coefficient of the substrate material in the form of AW7075 PM is $0.480 \pm 0.039$, however, this material is characterised by a much less stable course of the curve.

a)

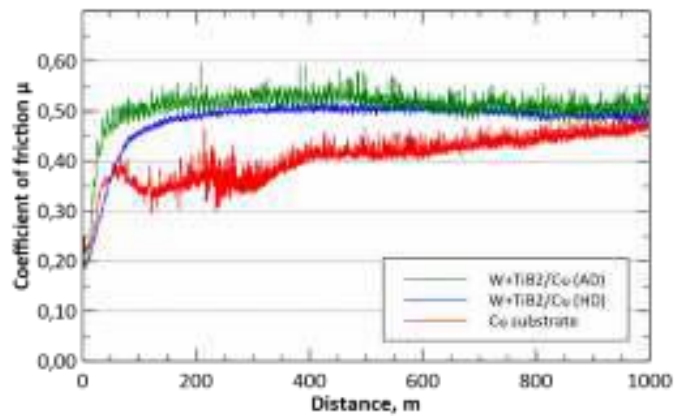

b)

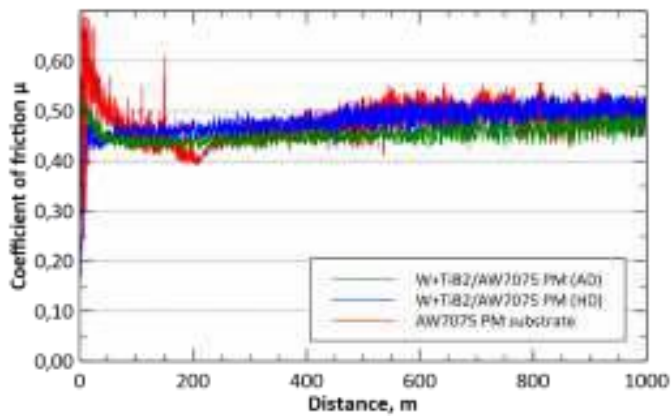

Fig. 5. Friction coefficient changes as a function of sliding distance 
The analysis of wear of the tested materials showed that in each cases a higher degree of wear was obtained for a substrate as compared to the substrate with the deposited layer. The produced composite layers are characterised by relatively low wear, which is confirmed by microscopic examination of the wear track (Fig. 6). The weight loss of layers deposited on a copper substrate was $0.0005 \mathrm{~g}$ for $\mathrm{W}+\mathrm{TiB}_{2} / \mathrm{Cu}(\mathrm{AD})$ and $0.0007 \mathrm{~g}$ for $\mathrm{W}+\mathrm{TiB}_{2} / \mathrm{Cu}(\mathrm{HD})$. The copper substrate was characterised by the level of wear of $0.0011 \mathrm{~g}$. Similarly, in the case of a substrate made of aluminum alloy (wear at the level of $0.0106 \mathrm{~g}$ ), a higher wear was obtained than in the case of AW7075 substrates with a deposited layer for which the obtained wear was $0.0063 \mathrm{~g}$ for $\mathrm{W}+\mathrm{TiB}_{2} / \mathrm{AW} 7075$ (AD) and $0.0069 \mathrm{~g}$ for $\mathrm{W}_{+} \mathrm{TiB}_{2} / \mathrm{AW} 7075$ (HD). In the tested materials, there was no loss of weight of the counter-sample, which was a ball made of $\mathrm{Al}_{2} \mathrm{O}_{3}$.

a)

C)

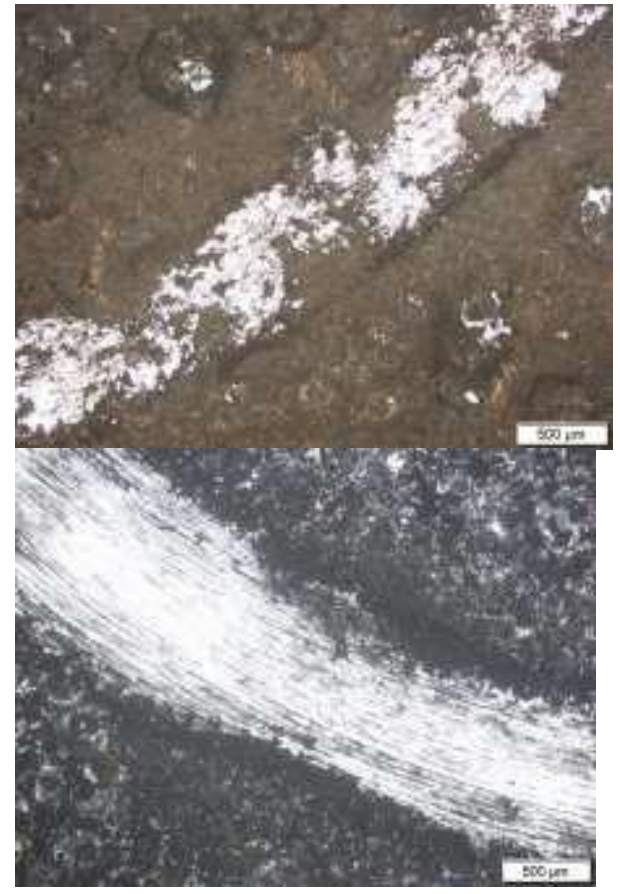

b)

d)

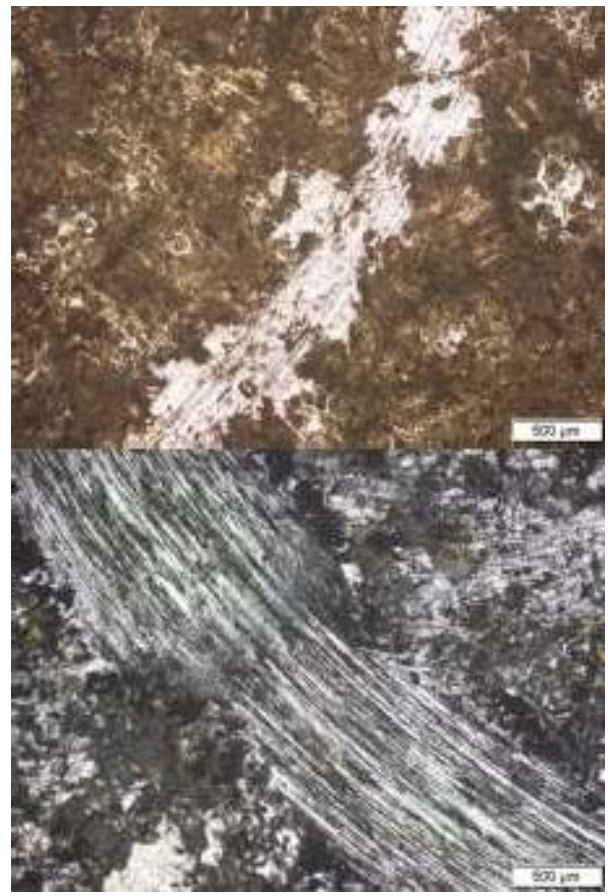

Fig. 6. Wear track surface after interaction with a counter-sample $\left(\mathrm{Al}_{2} \mathrm{O}_{3}\right.$ ball): $\mathrm{W}+\mathrm{TiB}_{2} / \mathrm{Cu}(\mathrm{AD})(\mathrm{a})$, $\mathrm{W}+\mathrm{TiB}_{2} / \mathrm{Cu}(\mathrm{HD})(\mathrm{b}), \mathrm{W}+\mathrm{TiB}_{2} / \mathrm{AW7075}$ (AD) (c), W+TiB $/$ AW7075 (HD) (d)

\section{CONCLUSIONS}

The analysis of the test results showed that it is possible to produce high-quality composite materials using the spark plasma sintering method, performing the role of electrodes in the electro-spark deposition process. The ESD method was successfully used for the deposition of the $\mathrm{W}_{+} \mathrm{TiB}_{2}$ composite coating of hard wear-resistant layers on non-ferrous substrates.

The powder mixture $\mathrm{W}+30$ vol. \% $\mathrm{TiB}_{2}$ obtained in laboratory conditions was characterised by high homogeneity in the entire volume, which indicates the correct course of the mixing process.

The applied SPS parameters allowed to obtain high-density composite sinters, corresponding to approx. $95.3 \%$ of theoretical density $\left(14.83 \mathrm{~g} / \mathrm{cm}^{3}\right)$. XRD analysis showed the occurrence of the WB phase (with a tetragonal 141/amd and orthorhombic $\mathrm{Cmcm}$ structure) and $\mathrm{W}_{2} \mathrm{~B}$ (with a tetragonal $14 / \mathrm{mcm}$ structure) in the sinters. There were also diffraction reflections of low intensity which correspond to different titanium oxides (Ti-O). The trace amount of carbon found in the analysed sinters is due to the use of graphite inserts in the SPS process.

The use of both the traditional manual method of deposition and automatic electro-spark deposition allowed to obtain good quality coatings on substrates made of non-ferrous metals. The obtained coatings, despite the roughness which is a characteristic feature of this type of process, are characterised by a good metallurgical bonding both with the copper substrate and the substrate made of an aluminium alloy (AW7075). The XRD analysis showed that in the produced coatings the dominant phases are the $\mathrm{W}_{2} \mathrm{~B}$ and $\mathrm{WB}$ phases.

The analysis of tribological tests showed that the tested coatings were characterised by an increased resistance to wear as compared to the substrate material. In addition, all tested layers were 
characterised by a stable course of changes in friction coefficient as a function of sliding distance. The obtained layers were characterised by the following average value of friction coefficient: 0.506 for $\mathrm{W}+\mathrm{TiB}_{2} / \mathrm{Cu}(\mathrm{AD}), 0.482$ for sample $\mathrm{W}+\mathrm{TiB}_{2} / \mathrm{Cu}(\mathrm{HD}), 0.453$ for $\mathrm{W}+\mathrm{TiB}_{2} / \mathrm{AW7075}(\mathrm{AD})$ and 0.481 for the layer manually deposited on the substrate made of an aluminium alloy.

The authors of the study intend to continue research on the production of composite sinters (including: $\mathrm{Ni}+\mathrm{TiB}_{2}, \mathrm{Cu}+\mathrm{TiB}_{2}, \mathrm{WC} / \mathrm{TiC}$ ) with the spark plasma sintering (SPS) method, performing the role of electrodes in the electro-spark deposition process of depositing wear-resistant coatings. It is planned that the produced layers will be successfully used for tools for ultrasonic cutting as well as for components which operate under extreme conditions, i.e. intensive wear conditions, in order to increase their lifetime. The advantage of composite electro-spark deposition layers is the possibility of conducting the processes locally, in the selected part of a detail.

\section{ACKNOWLEDGEMENTS}

Project APVV SK-PL-2015-0003 "Wear resistant and electrically conductive composite coatings on nonferrous metals" within the framework of the Polish and Slovakian programme for exchange of personnel participating in scientific and research projects in 2016-2017, financially supported from the Ministry of Science and Higher Education under the agreement between the Government of the Republic of Poland and the Government of the Slovak Republic on scientific and technological cooperation and the Slovak Research and Development Agency under agreement No. SKPL-2015-0003 and Slovak Grant Agency - VEGA grant 2/0044/17.

\section{REFERENCES}

[1] J. Kulasa, B. Juszczyk, J. Kováčik, Š. Emmer, S. Malara, W. Malec, M. Lis: Wear resistant and electrically conductive composite coatings on non-ferrous metals, European Congress and Exhibition on Advanced Materials and Processes, 17-22 September 2017, Thessaloniki, Greece, EUROMAT 2017

[2] J Kováčik, Š. Emmer, J. Kulasa, M. Lis, S. Malara, J. Rodriguez, I. Cañadas: W-TiB 2 composite material for Electro-spark deposition, 7th International Conference on Advanced Materials and Structures - AMS 2018, 28-31.03.2018 r., Timisoara, Romania

[3] R.N. Johnson, G.L. Sheldon: Advances in the electrospark deposition coating process, Journal of Vacuum Science \& Technology A, Vol. 4, 1986, pp. 2740-2746, DOI: 10.1116/1.573672

[4] J.L. Reynolds, R.L. Holdren, L.E. Brown: Electro-spark deposition, Advanced Materials and Processes, Vol. 161, No. 3, 2003, pp. 35-37

[5] S. Peterkin: Electro-Spark Deposition Machine Design, Physical Controls and Parameter Effects, Canada 2016

[6] J. Kováčik, P. Baksa, S. Emmer: Electro Spark Deposition of TiB2 Layers on Ti6Al4V Alloy, Acta Metallurgica Slovaca, Vol. 22, 2016, No. 1, pp. 52-59

[7] TWI Ltd: What is electrospark deposition (ESD)? Frequently asked Questions, TWI Ltd, 2016. [Online]. Available: http://www.twi-global.com/technical-knowledge/faqs/process-faqs/faq-what-iselectrospark-deposition-esd/. [Accessed on 20 October 2016]

[8] P. Luo, S. Dong, A. Yangli, S. Sun, Z. Zheng, H. Wang: Electrospark deposition of $\mathrm{Al}_{2} \mathrm{O}_{3}-\mathrm{TiB}_{2} / \mathrm{Ni}$ composite-phase surface coatings on $\mathrm{Cu}-\mathrm{Cr}-\mathrm{Zr}$ alloy electrodes, Journal of Asian Ceramic Societies 3, 2015, pp.103-107

[9] P. Luo, S. Dong, A. Yangli, S. Sun, Z. Zheng: Electrospark deposition of ZrB $\mathrm{Zr}_{2}-\mathrm{TiB}_{2}$ composite coating on Cu-Cr-Zr alloy electrodes, Int. J. Surface Science and Engineering, Vol. 10, No. 1, 2016

[10] I. Gibson, D.W. Rosen, B. Stucker, 2015, Additive Manufacturing Technologies: 3D Printing, Rapid Prototyping, and Direct Digital Manufacturing, Springer, pp. 1-498. 